\title{
Evaluation of late blight control in potato cultivars for organic or reduced input production in Northern Ireland
}

L R Cooke, G Little

Agri- Food \& Biosciences Institute, Belfast, United Kingdom

Email: louise.cooke@afbini.gov.uk

Introduction Late blight, caused by Phytophthora infestans, may result in total loss of organic potato crops in Northern Ireland. Trials in Belfast (Cooke and Little, 2004) showed that cultivars with partial blight resistance could withstand high infection pressure. In this study, performance was evaluated against the current $P$. infestans population, containing A1 and A2 mating types (Cooke et al., 2009).

Materials and methods The trials were planted (6 May 2008, 5 June 2009) at the Agri-Food \& Biosciences Institute, Belfast in a split-plot design with fungicide regimes as main plots, four cultivars as sub-plots and four replicate blocks. The cultivars/clones (rated on a 1-9 scale for foliage and tuber blight resistance, respectively, where 9 is maximum resistance), were, in both years, Santé $(7,6)$ and Sárpo Mira (7, 9), with, in 2008 Galactica $(7,7)$ and Setanta $(8,9)$, and in 2009 Sunset $(7,5)$ and AFBI Loughgall clone L5937/2 (7, 7). Ratings were from the British Potato Variety Database except for L5937/2 (breeder's estimates). Each sub-plot comprised two drills x 10 tubers of each cultivar (3 x $1.5 \mathrm{~m})$. Main plots were separated by unsprayed drills of cv. Désirée. In 2008 these were inoculated (early July) with N. Ireland P. infestans isolates (A1 and A2 types) to provide an infection source. In 2009, because natural infection was observed in early July, the trial was not inoculated. The treatment regimes included no fungicide and a programme based on the non-systemic fluazinam (150 g a.i./ha as 'Shirlan', Syngenta, $300 \mathrm{ml} / \mathrm{ha}$ ) applied at extended intervals. In 2008 four fluazinam applications were made (2, 28 July, 8, 27 August) and in 2009 two (22 July, 12 August). Foliage blight was assessed twice weekly on all drills after blight was seen until haulm destruction (29 August 2008; 4 September 2009). The trials were lifted on 4 November 2008 and 1 October 2009. The yield from each plot was graded and the number and weight of blighted tubers recorded. The remaining healthy tubers were stored until January when they were re-assessed for tuber blight. Data were subjected to analyses of variance.

Results In both years, foliage infection built up rapidly favoured by wet weather. In 2008, the unsprayed Santé and Galactica were almost dead by 8 August (Table 1), Setanta survived a week longer, but Mira had only $23 \%$ infection on 29 August. Fluazinam application delayed blight development as indicated by the smaller Area Under the Disease Progress Curve (AUDPC, Table 1); after mid-August build up was slower in Setanta than in Santé and Galactica, while Mira had few blight lesions by 29 August. The presence of other rots (notably pink rot, P. erythroseptica) favoured by very wet soil complicated tuber blight and yield assessments; Mira had the greatest yield of healthy tubers for both untreated and fluazinam-treated plots, but differences were not significant. In 2009, Mira again developed significantly less foliage blight than any other cultivar in both untreated and fluazinam-treated plots, while foliar infection was slower to build up in Sunset and L5937/2 than in Santé. Yield and tuber blight data for 2009 are not yet available.

Table 1 Foliage blight, tuber blight and yield of potato cultivars, 2008 and 2009 trials

\begin{tabular}{|c|c|c|c|c|c|c|c|c|c|}
\hline \multirow{2}{*}{\multicolumn{2}{|c|}{$\begin{array}{l}\text { Year/ } \\
\text { cultivar }\end{array}$}} & \multicolumn{2}{|c|}{ Foliage blight $(\%)^{\mathrm{a}}$} & \multicolumn{2}{|c|}{$\mathrm{AUDPC}^{\mathrm{b}}$} & \multicolumn{2}{|c|}{ Tuber blight and rots (\%) } & \multicolumn{2}{|c|}{ Yield (kg/plot) } \\
\hline & & $\mathrm{U}$ & $\mathrm{F}$ & $\mathrm{U}$ & $\mathrm{F}$ & $\mathrm{U}$ & $\mathrm{F}$ & U & $\mathrm{F}$ \\
\hline \multirow[t]{4}{*}{$\underline{2008}$} & Santé & 95.0 & 7.8 & 2417 & 1400 & 1.73 & 2.30 & 16.74 & 20.23 \\
\hline & Galactica & 95.0 & 11.5 & 2456 & 1485 & 8.33 & 5.92 & 14.82 & 18.42 \\
\hline & Setanta & 37.5 & 7.8 & 1977 & 1042 & 1.98 & 2.31 & 15.21 & 20.69 \\
\hline & Mira & 1.1 & 0.0 & 281 & 13 & 6.18 & 5.80 & 18.86 & 23.09 \\
\hline \multicolumn{2}{|c|}{ L.S.D. $(P<0.05)$} & \multicolumn{2}{|c|}{5.99} & \multicolumn{2}{|c|}{211.8} & \multicolumn{2}{|c|}{11.73} & \multicolumn{2}{|r|}{6.551} \\
\hline \multirow[t]{4}{*}{$\underline{2009}$} & Santé & 95.0 & 27.5 & 3345 & 2064 & \multicolumn{2}{|c|}{ - } & \multicolumn{2}{|c|}{-} \\
\hline & Sunset & 71.2 & 20.1 & 2656 & 1203 & \multicolumn{2}{|c|}{-} & \multicolumn{2}{|c|}{-} \\
\hline & L5937/2 & 85.0 & 21.0 & 3019 & 1254 & \multicolumn{2}{|c|}{ - } & \multicolumn{2}{|c|}{-} \\
\hline & Mira & 3.9 & 0.0 & 247 & 86 & \multirow{2}{*}{\multicolumn{2}{|c|}{-}} & \multicolumn{2}{|c|}{-} \\
\hline \multicolumn{2}{|c|}{ L.S.D. $(P<0.05)$} & \multicolumn{2}{|c|}{26.01} & \multicolumn{2}{|c|}{816.6} & & & & \\
\hline
\end{tabular}

"a early August assessments: 8 August 2008, 6 August 2009; ${ }^{\mathrm{b}}$ Area Under Disease Progress Curve; U untreated, fluazinam-treated

Conclusions Despite the presence of $P$. infestans genotypes including the aggressive 'blue 13' A2 (data not presented), in 2008 and 2009 Mira proved very resistant to foliage blight. Cvs. Santé and Galactica proved too susceptible to be grown without fungicide, but inputs may be reduced with cv. Setanta. Sunset and L5937/2 also appear promising, but results of the yield and tuber blight assessments are needed before it can be ascertained if they should be evaluated further.

Acknowledgements The authors thank P. Watts (AFBI Loughgall) for providing L5937/2, Mark Wilson (AFBI) and Queen's University students for their technical assistance and DARD for funding.

\section{References}

Cooke, L.R. and Little, G. 2004. PPO-Special Report No. 10, 73-82.

Cooke, L.R., Little, G., Armstrong, C., Thompson, J.M., Griffin, D., Dowley, L.J., Kildea, S., Perez, F.M. and Deahl, K.L. 2009. PPO-Special Report No. 13, 183-189. 